\title{
Narrativas formativas: método e fenômeno de pesquisa a ser aplicado na formação docente
}

\author{
Formative narratives: method and research phenomenon to be applied in teacher \\ education
}

\section{Resumo}

\author{
Bruna Duarte Ferreira Frohmut ${ }^{1}$ \\ Rodrigo Avella Ramirez ${ }^{2}$
}

As narrativas formativas são utilizadas tanto como um instrumento de formação docente, para análise das dimensões pessoal e profissional do professor, como também método em pesquisas acadêmicas para acessar o percurso de vida e formação dos sujeitos. Este estudo objetiva, por meio de uma análise bibliométrica, verificar a aplicação das narrativas formativas em pesquisas acadêmicas, a partir de artigos sediados no Portal de Periódicos CAPES, no período de 1994 a 2019 e estimar o quanto estas foram empregadas na área de educação, especificamente na educação profissional. Esse objetivo foi guiado pela seguinte questão: as narrativas formativas são aplicadas como método para coleta de dados e analisadas como fenômeno de pesquisa na formação docente na educação profissional? Adota-se uma abordagem quantitativa e os resultados indicam que as narrativas formativas são utilizadas em estudos acadêmicos, concentrados, na área de educação, destacando-se na educação superior, porém ainda são pouco exploradas na educação profissional.

Palavras-chave: Investigação Narrativa; Histórias de Vida; Aprendizagem docente; Educação Profissional e Tecnológica.

\begin{abstract}
Formative narratives are used both as an instrument of teacher training, for the analysis of the personal and professional dimensions of the teacher, as well as a method in academic research to access the life and training of subjects. This study aims, through a bibliometric analysis, to verify the application of formative narratives in academic research based on articles based on the CAPES Journal Portal in the period from 1994 to 2019 and to estimate how much they were used in the area of education, specifically in professional education. This objective was guided by the following question: are formative narratives applied as a method for data collection and analyzed as a research phenomenon in teacher education in professional education? A quantitative approach is adopted, and the results indicate that formative narratives are used in academic studies, concentrated in the area of education, standing out in higher education, but are still little explored in professional education.
\end{abstract}

\footnotetext{
${ }^{1}$ Mestranda do Programa de Mestrado Profissional em Gestão e Desenvolvimento da Educação Profissional (CEETEPS/SP); Professora do ensino técnico do eixo de controle e processos industriais no Centro Paula Souza; São Paulo - SP; E-mail: brunafrohmut@gmail.com

${ }^{2}$ Doutor em Educação (Mackenzie/SP); Docente do Programa de Mestrado Profissional em Gestão e Desenvolvimento da Educação Profissional (CEETEPS/SP); São Paulo - SP; E-mail: roram1000@ hotmail.com
} 
Keywords: Narrative Research; Life stories; Teacher education; Professional and Technological Education.

\section{Introdução}

A publicação da história de um imigrante polonês que chegou aos Estados Unidos antes da primeira guerra mundial deu início, sob influência da Escola de Chicago, aos estudos acadêmicos sobre histórias de vida. Em 1919, W.I. Thomas e F. Znaniecki publicam Le Paysan Polonais, em que adotam a abordagem das histórias de vida para retratar a realidade social vivida por imigrantes nos Estados Unidos daquela época (FERNANDES; LOPES, 2011).

Com as mudanças de paradigmas no final da década de 1970 em relação à história cultural, de acordo com Fernandes e Lopes (2011) ocorre uma valorização pelos processos cotidianos das práticas culturais e sociais, assim, as investigações narrativas são retomadas nesse campo, o que favorece o desenvolvimento das pesquisas com histórias de vida na perspectiva da formação.

Para Antunes (2011) cada história de vida não é um percurso linear, esta se constrói de forma estruturada e por ciclos. O processo de formação de um indivíduo é complexo, por ser atravessado por diferentes variáveis contidas nas dimensões culturais e sociais que este pertence e se identifica.

Josso (2007) define as narrações centradas na formação ao longo da vida como uma forma de revelar os sentidos múltiplos de existencialidade singular-plural, criativa e inventiva do pensar, do agir e do viver junto.

Assim, a investigação narrativa explora as histórias vividas e contadas. Essas histórias são, por sua vez, resultantes da combinação entre influências sociais sobre o indivíduo, influências sociais sobre o ambiente, além da trajetória individual (RAMIREZ, 2017).

Nesse contexto, as narrativas formativas são significativas para a coleta de dados para estudos acadêmicos. Assim, faz-se necessário conhecer a produção acadêmica, a aplicação em pesquisas e a expansão das narrativas formativas na comunidade científica, pois o processo de formação do sujeito, bem como a formação docente, é construído pelos fatores culturais e sociais presentes em sua história de vida. 
As publicações nacionais e internacionais, disponibilizadas no Portal de Periódicos da CAPES - Coordenação de Aperfeiçoamento de Pessoal de Nível Superior, mantida pelo Ministério da Educação (MEC), têm como objetivo atender as demandas da comunidade acadêmica brasileira (CAPES, 2020).

Conforme citado por Langhi e Macedo (2018) o Portal de Periódicos CAPES é um recurso que facilita a consulta de diversos periódicos e, consequentemente de artigos, ou seja, é uma biblioteca virtual que permite que, de forma online, via internet, o conteúdo seja acessado, destacando que o acesso pode tanto ser gratuito como também há o conteúdo assinado.

Este estudo tem por objetivo coletar dados quantitativos sobre a produção científica sediada no Portal de Periódicos da Capes, sobre narrativas formativas, utilizando apenas o conteúdo aberto gratuito. Referente à utilização das narrativas formativas como recurso de pesquisa, buscou-se verificar especificamente, na literatura analisada, nos períodos de 1994 a 2019, a aplicação das narrativas formativas como recurso de pesquisa e estimar o quanto essas produções foram empregadas na área de educação, especificamente na educação profissional.

Também foi analisada a quantidade de artigos publicados anualmente desde a criação da Associação Brasileira de Pesquisa (Auto) Biográfica e o Congresso Internacional sobre Pesquisa (Auto) biográfica (CIPA), além de quantificar os grupos de pesquisas no Brasil que utilizam a pesquisa (Auto) biográfica em seus estudos, bem como a participação das instituições de ensino no CIPA e, consequentemente, compreender como está a expansão das narrativas formativas na comunidade científica brasileira atualmente.

\section{As narrativas formativas}

A pesquisa a partir da narração das histórias de vida, também denominada como narrativas formativas, têm como objetivo evidenciar e questionar as heranças, a continuidade, a ruptura, os projetos de vida, as aquisições de experiências etc. As subjetividades exprimidas (o pensar, o sensibilizar-se, o imaginar, o emocionar-se, o apreciar, o amar) são exploradas e confrontadas. Essas reflexões fundamentadas pela narrativa da formação de si permitem estabelecer a medida das mudanças sociais e culturais nas vidas singulares e relacioná-las com a evolução dos contextos de vida profissional e social. Assim, o trabalho sobre essa 
subjetividade singular e plural torna-se uma das prioridades da formação em geral e do trabalho de narração das histórias de vida em particular (JOSSO, 2007).

As narrativas formativas conforme descreve Antunes (2011) permitem compreender a construção de uma história de vida, pois referem-se, efetivamente, a um conjunto de acontecimentos estruturantes mais ou menos transversais a todas as histórias de vida que abrangem os ciclos, as etapas e as fases que podem ser de ruptura e/ou transição, mas que constituem sempre momentos formadores.

Apresentar a vida das pessoas na globalidade de sua história, as variações dos acontecimentos que essas expressam, bem como as múltiplas facetas recordadas em seus percursos têm como desafio identificar as relações entre as dimensões psicossomáticas, psicológicas, sociológicas, antropológicas, sócio-históricas, espirituais, por exemplo, que intervêm na expressão da identidade de alguém. Por isso, é importante ressaltar que os estudos que utilizam as narrativas formativas em suas pesquisas, evidenciam a exigência metodológica de pensar as facetas existenciais da identidade através de uma abordagem multirreferencial que integra os diferentes registros do pensar humano (as crenças científicas, crenças religiosas, esotéricas), assim como as diferentes dimensões de nosso ser no mundo. (JOSSO, 2007).

Ramirez (2017) aponta que pelo fato de se fundamentar na experiência, a narrativa formativa é tanto método de pesquisa como fenômeno pesquisado, e nesse sentido o processo de formação do sujeito é algo construído e que por meio das narrativas é possível encontrar muitos dos sentidos na vida desse sujeito em formação.

Aprender a partir de uma experiência para Dewey (2000) é estabelecer uma conexão com o passado e com o futuro, e entre o fazer e sentir em termos de prazer e dor. Em tais condições, o pensamento cometido na experiência permite a descoberta de conexões detalhadas das nossas atividades e das suas consequências.

Larrosa (2002) destaca a experiência como algo que "nos passa", ou que nos toca, ou que nos acontece, e assim, ao nos passar, nos forma e nos transforma e pensar sobre estas experiências não é somente "raciocinar" ou "calcular" ou "argumentar", como nos tem sido ensinado algumas vezes, mas é, sobretudo, dar sentido ao que somos e ao que nos acontece.

$\mathrm{Na}$ construção de narrativas de experiências vividas, há um processo reflexivo entre o viver, contar, reviver e recontar de uma história de vida, o que para Clandinin e Connelly (2015) indicam que a pesquisa narrativa está intimamente associada à teoria da experiência de 
Dewey, principalmente quanto às noções de situação, continuidade e interação, já que esta contempla as esferas do pessoal e social (interação), do passado, presente e futuro (continuidade), dos combinados à noção de lugar (situação). Com isso, a pesquisa narrativa permite criar um espaço tridimensional para investigação narrativa, com a temporalidade ao longo da primeira dimensão, o pessoal e o social ao longo da segunda dimensão e o lugar ao longo da terceira. Vale ressaltar que qualquer investigação em particular é definida por este espaço tridimensional: os estudos têm dimensões e abordam assuntos temporais; focam no pessoal e no social em um balanço adequado para a investigação; e ocorrem em lugares específicos ou sequencias de lugares, e assim, a pesquisa narrativa compreende e atua nestas esferas.

A pesquisa a partir da narração das histórias de vida, também sendo denominada de narrativas formadoras têm como objetivo evidenciar e questionar as heranças, a continuidade, a ruptura, os projetos de vida, as aquisições de experiência, etc. As subjetividades exprimidas (o pensar, o sensibilizar-se, o imaginar, o emocionar-se, o apreciar, o amar) são exploradas e confrontadas. Essas reflexões fundamentadas pela narrativa da formação de si permite estabelecer a medida das mudanças sociais e culturais nas vidas singulares e relacioná-las com a evolução dos contextos de vida profissional e social. Assim, o trabalho sobre essa subjetividade singular e plural torna-se uma das prioridades da formação em geral e do trabalho de narração das histórias de vida em particular (JOSSO, 2007).

\section{Narrativas formativas e a formação docente}

Nas últimas décadas, por influência de órgãos internacionais tais como: Organização das Nações Unidas para a Educação, a Ciência e a Cultura (UNESCO); a Organização dos Estados Ibero-americanos para a Educação, a Ciência e Cultura (OEI) e a Organização de Cooperação e Desenvolvimento Econômico (OCDE) e, em virtude de mudanças sociais, econômicas e culturais, as agendas global e regional de governo de diversos países apresentam como destaque o tema sobre a formação de professores (FIORENTINI, CRECCI, 2013).

A pesquisa narrativa apresenta-se como uma alternativa para lidar com a questão de método de pesquisa e abordagens ao desenvolvimento profissional do docente, com o objetivo de proporcionar espaço e oportunidade para os professores recuperarem, reconstituírem e 
representarem os significados de suas experiências, o que torna possível trazer à superfície os saberes manifestados da experiência pedagógica. Com isso, a abordagem biográfica e a autobiografia de formação podem possibilitar ao sujeito a tomada de consciência de si e de suas aprendizagens experienciais, uma vez que essa implica na reflexão de determinado tema, de determinadas práticas pedagógicas, da própria formação e/ou da própria vida, o que resulta em uma variação no processo de aprendizagem docente (FREITA e GHEDIN, 2015; BARBISAN e MEIGID, 2018).

Barbisan e Meigid (2018) ressaltam que as narrativas surgiram como um recurso para dar "voz" às minorias, aos grupos dos excluídos ou desprezados, o que permitiu que essas vozes fossem efetivamente ouvidas, assim, sob essa ótica foi que se deu o impulso do "contar sobre si e sua formação" e, com isso, se extrapolou para a área educacional, foi possível perceber a possibilidade de socialização e divulgação das experiências docentes com o uso das narrativas.

Por trás de um professor há uma pessoa, assim, Nóvoa (1992) aponta ser necessária a interação entre as dimensões pessoais e profissionais, o que possivelmente permitirá ao docente apropriar-se dos seus processos de formação e dar sentido para a sua história de vida.

Para Tardif (2014) uma pessoa que ensina durante trinta anos, por exemplo, não exerce apenas uma atividade, mas exerce algo de si mesma, sua identidade carrega as marcas de sua atividade, assim como sua existência é configurada por sua atuação profissional. Com o passar do tempo este profissional torna-se um professor com sua cultura, suas ideias, suas funções, seus interesses etc. Porém, cabe ressaltar que a relação dos docentes com os seus saberes não se resume simplesmente a função de transmitir conhecimentos já constituídos. A prática da docência integra diferentes saberes. É um saber plural, oriundos da formação profissional e de saberes disciplinares, curriculares e experienciais. Portanto, são saberes temporais, existenciais, sociais e pragmáticos.

Por isso, as narrativas de histórias de vida de professores refletem sobre a constituição da identidade docente, pois considerada essa dinâmica das interações biográficas, busca atentar-se aos modos de ser, de tornar-se e de ver-se professor no exercício da docência e como se constrói a formação do sujeito aprendiz, como aprendemos (PAIVA, 2012; RAMIREZ 2014).

O exercício da docência é um trabalho complexo, pois é realizado com e sobre pessoas, com finalidades, intencionalidades, formas de engajamento, prescrições e programas. 


\section{OO DEVIR EDUCAÇÃO}

ISSN: 2526-849X

Por ser uma ação baseada em vínculos, a formação para este trabalho também é complexa. Por isso, formar professores envolve uma lógica socioprofissional, didática e psicológica e essa formação deve propiciar a construção de mudanças conceituais e práticas (GATTI, 2019).

Em seus estudos, Mizukami (2011) destaca que a profissão docente é complexa e, assim como as outras profissões, é aprendida. O processo de formação docente, ou seja, a aprendizagem e o desenvolvimento profissional da docência são processos que se constituem ao longo da vida e esses são lentos.

Tardif (2014) em sua obra também evidencia que no exercício da docência, assim como em qualquer profissão, o tempo é um fator importante para edificação e compreensão dos saberes docentes, ou seja, a dominação dos saberes profissionais para a realização do trabalho. Assim, os saberes docentes são temporais, são adquiridos pelos processos de aprendizagem e de socialização e esses cruzam tanto sua história de vida quanto sua carreira, na qual estão presentes dimensões identitárias.

A formação de professores para Shulman (2014) tem por objetivo educá-los para refletir em profundidade suas práticas pedagógicas e não doutrinar ou treinar docentes para se comportar de forma prescrita. Para ocorrer essa reflexão profunda, os professores precisam aprender a raciocinar a partir da base de seu conhecimento, que estão ancorados em fatos, princípios e experiências. Por isso, trabalhar as crenças que guiam as ações docentes é necessário para a formação de professores.

Nóvoa (1992) defende uma formação de professores que estimule uma perspectiva crítico-reflexivo, ou seja, que forneça aos docentes meios de um pensamento. A formação não se constrói por acumulação (de cursos, de conhecimentos ou de técnicas), mas por meio de um trabalho que permita a reflexividade crítica sobre as práticas e de (re) construção permanente de uma identidade pessoal. Portanto, é importante o investimento pessoal e dar um estatuto ao saber da experiência Esse tipo de formação proporciona a construção de uma identidade, que é também uma identidade profissional.

Porém, Peterossi e Menino (2017) apontam que diferentemente dos professores de Educação Básica, que já têm definido há décadas o trajeto de sua formação e profissionalização, a única certeza da formação para o professor da Educação Profissional será de forma especial e emergencial, ou seja, não é a mesma dos demais. A formação para 
professores da Educação Profissional também não evoluiu em direção a definições e nem diretrizes estabelecidas por marcos regulatórios próprios ao longo desses anos.

Por fim, Mizukami (2006) ressalta que na formação do formador por se tratar de um processo continuado e de autoformação, já que este envolve as dimensões individuais, coletivas e organizacionais e que são desenvolvidos em determinados contextos, momentos diversificados e em diferentes comunidades de aprendizagem composta por outros formadores, se faz necessário o desenvolvimento da atitude investigativa como eixo de formação, para a construção de uma base de conhecimento sólida e flexível, tendo como objetivo a aprendizagem da docência, acompanhada da construção de estratégias de desenvolvimento profissional que não sejam invasivas e que permitam objetivação de crenças, valores e teorias pessoais.

\section{A expansão das narrativas formativas na pesquisa científica}

Fernandes e Lopes (2011) apontam em seus estudos um crescimento no uso da abordagem biográfica, na acepção de pesquisas narrativas ou com histórias de vida e que tem ocorrido em diversas áreas do conhecimento das ciências sociais e humanas desde as últimas décadas do século XX até os dias atuais. Na área de educação, é utilizada tanto como um instrumento de formação docente, para análise das dimensões pessoal e profissional do professor, como também em pesquisas acadêmicas, como um método de acesso ao percurso de vida e formação de diversos sujeitos da educação.

Há mais de duas décadas as narrativas são aplicadas na formação docente e na pesquisa, e esta temática ganhou espaço no Brasil a partir dos anos de 1990, sendo Nóvoa o pioneiro com as histórias de vida de professores, seguido por Connelly e Clandinin também nesta mesma década, entre outros teóricos (LIMA; GERALDI; GERALDI, 2015).

A formação de um indivíduo, bem como de um docente, é marcada pelos fatores decorrentes de suas vivências e história de vida. Nesse sentido, a pesquisa narrativa, conforme abordada por Clandinin e Connelly (2015) pode ser descrita como o estudo da experiência como história, assim, é principalmente uma forma de pensar sobre a experiência.

$\mathrm{O}$ uso da pesquisa narrativa como método e fenômeno de pesquisa aplicado as temáticas de processo de formação dos sujeitos ocorreu conforme Fernandes e Lopes (2011) 
em três períodos de acordo com as datas de edição de produções escritas, criação de fundações de associações, de rede e de diplomas de formação.

O primeiro período, denominado de período de eclosão, ocorreu com as publicações que representam a gênese de uma mudança paradigmática na pesquisa científica, que buscou ressignificar os acontecimentos pessoais e sociais no processo formativo dos indivíduos (FERNANDES; LOPES, 2011).

Conforme descrito por Josso (2004) e Fernandes e Lopes (2011), a publicação do livro Produire sa vie: autoformation et autobiographie e a formação da rede sobre História de vida e formação, ambos em 1983 por Gaston Pineau; o lançamento de dois números da revista francesa Education permanente intitulados Les histoires de vie entre la recherche et la formation, em 1984; a realização de um colóquio sobre histórias de vida na Universidade de Tours, França; a publicação do livro $O$ método (auto)biográfico e a formação, de Antonio Nóvoa e Matthias Finger da Universidade de Lisboa e a obra Histoires de vie, publicada em dois tomos, sob a coordenação de Pineau e Jobert em 1989, são exemplos das obras seminais sobre essa abordagem metodológica.

O segundo período como período de fundação, com a criação da L'Association Internacionale des histoires de vie en fomation (ASIHVIF), em 1990, o que propiciou a organização em diversos países de associações e redes nacionais e regionais semelhantes a esta, que aconteceram na Suíça, em Quebec e na França, por exemplo. Nesse mesmo período houve também o lançamento em Paris da Coleção Histoire de vie et formation, no ano de 1996. Assim, o diálogo e o intercâmbio com a Associação Internacional e a consolidação das pesquisas permitiu fortalecimento deste movimento no Brasil (JOSSO, 2004; FERNANDES; LOPES, 2011).

Finalmente, o terceiro caracteriza-se como o desenvolvimento diferenciado que se inicia a partir dos anos 2000 com a refundação de associações, retomada de colóquios e pela emergência de novos autores e atores que contribuíram para o fortalecimento do movimento com novas publicações e ações, originando abordagens que visavam responder às novas questões teóricas e metodológicas. O resultado desse movimento gerou o I Congresso Internacional sobre Pesquisa (auto) biográfica (CIPA) na cidade de Porto Alegre em 2004, que permitiu a criação de uma rede de pesquisa (auto) biográfica brasileira (FERNANDES; LOPES, 2011). 
No ano de 2008 com a cooperação institucional das agências governamentais de incentivo ao desenvolvimento da pesquisa - CAPES (Coordenação de Aperfeiçoamento de Pessoal de Nível Superior) e CNPq (Conselho Nacional de Desenvolvimento Científico e Tecnológico) - e também com o apoio das fundações de amparo à pesquisa (FAPERGS (Fundação de Amparo à Pesquisa do Estado do Rio Grande do Sul), FAPESB (Fundação de Amparo à Pesquisa do Estado da Bahia), FAPERJ (Fundação de Amparo à Pesquisa do Estado do Rio de Janeiro) e do INEP (Instituto Nacional de Estudos e Pesquisas Educacionais Anísio Teixeira e o número cada vez maior de instituições brasileiras como coorganizadoras do congresso, foi fundada e aprovada na Assembleia Final do III CIPA a Associação Brasileira de Pesquisa (Auto) Biográfica BIOgraph, uma associação científica sem fins lucrativos (BIOgraph, 2019).

A BIOgraph (2019) tem como objetivo de promover e coordenar estudos e pesquisas, eventos e ensino no âmbito da pesquisa (auto) biográfica, memória, histórias de vidas, narrativas formativas e práticas de formação; dialogar com associações congêneres, especialistas nacionais e internacionais e desenvolver ações interdisciplinares no campo de pesquisa-ensino; estimular a divulgação e informação das produções na área de pesquisa (auto) biográficas, memória, histórias de vidas e práticas de formação; promover a crítica e pluralismo teórico na área em suas diferentes produções e atividades e, por fim, congregar profissionais brasileiros que pesquisam (auto) biografias, memória, histórias de vidas e práticas de formação.

A BIOgraph desempenha um papel articulador responsável pelo êxito do CIPA), no que concerne à divulgação e circulação de informações entre os grupos de pesquisa e fortalecimento da área de pós-graduação em todo país e a interlocução, propiciando o avanço da pesquisa (auto) biográfica em diversos contextos educacionais, sociopolíticos e econômico-culturais um ponto vital para garantir a expansão da pesquisa (auto) biográfica no Brasil.

Fernandes e Lopes (2011) ainda destacam que o crescente uso das histórias de vida na formação fez surgir várias correntes e uma variedade de denominações tais como: biografias, (auto) biografias, relato de vida, narrativas formativas entre outras. É importante destacar que independente do nome que a abordagem narrativa receba, esse tipo de pesquisa utiliza distintas maneiras de narração para acessar e apreender as experiências formativas dos indivíduos, que pode se dar por meio de relatos orais e escritos, ou por meio de diários, 


\section{QO DEVIR EDUCAÇÃO}

ISSN: 2526-849X

memórias, cartas, entrevistas narrativas, fotografias, ateliês biográficos, o mais importante é que as vidas sejam narradas e relembradas, valorizando suas singularidades.

\section{Método}

O método quantitativo foi utilizado para o desenvolvimento da bibliometria, cuja finalidade é apurar a produção científica e o desenvolvimento de uma determinada área do conhecimento, sendo possível medir por intermédio de uma técnica quantitativa e estatística (ARAÚJO, 2006).

A primeira etapa do estudo foi a coleta dos dados realizada por meio do Portal de Periódicos Capes e análise dos artigos ocorreram no intervalo temporal de maio de 2019 a junho de 2020. Ao ser acessado, mostrou a seguinte informação: "Você está acessando o conteúdo gratuito do Portal. O conteúdo assinado está disponível para os acessos com IP identificado das instituições participantes.” (CAPES, 2020).

Ao realizar a busca por assunto: "Narrativas Formativas", surgiram 276 resultados, sendo, 219 periódicos revisados por pares, conforme ilustra a Figura 1. O resultado é referente aos anos de 1994 a 2019, sendo que 217 artigos foram utilizados para a realização da análise da pesquisa, pois 2 artigos estavam repetidos.

narrativas formativas

(ativas formativas

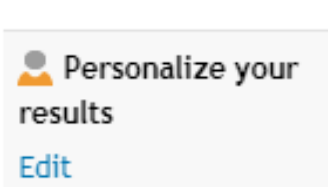

$\mathbf{x}$

Resultados de 1 - 10 para 276 para

Portal de Periodicos

Mostrar somente Periódicos revisados por pares (219)
Buscar

Figura 1: Tela de busca por Narrativas Formativas em 16 de junho de 2020 Fonte: Portal de Periódicos Capes, 2020

Vale destacar que há uma alteração no número de artigos que ainda são incluídos, devido ao lapso temporal que existe entre submissão, avaliação e publicação, portanto, os dados coletados e analisados até esse período (16 de junho de 2020), bem como anteriores a esse são passíveis de alterações tanto para mais como para menos, já que a biblioteca virtual da Capes disponibiliza material indexado por outras instituições (LANGHI; MACEDO, 2018). 
Os artigos analisados foram categorizados e quantificados de acordo com a área do conhecimento que aplicou as narrativas formativas como recurso em pesquisas acadêmicas, com o objetivo de verificar a quantidade de publicações anuais.

Em uma planilha do Microsoft Excel foram preenchidos os seguintes dados coletados dos artigos com revisão por pares pesquisados e analisados nos resultados da busca: autor (es), título do artigo, ano de publicação, idioma e área do conhecimento.

A leitura do resumo de cada artigo pesquisado foi feita com o intuito de classificar a área do conhecimento e identificar se a educação profissional estava presente dentre as áreas do conhecimento contempladas com o uso das narrativas formativas como recurso de pesquisa.

A segunda etapa do estudo realizou a coleta e análise das informações das informações disponibilizadas por meio do site da Associação Brasileira de Pesquisa (Auto) Biográfica Biograph ocorreram no intervalo temporal de setembro a novembro de 2019.

Assim, em outra planilha do Microsoft Excel foram preenchidos as seguintes informações disponibilizadas pelo site da BIOgraph: nome do grupo de pesquisa, instituição de ensino, nome do responsável pelo grupo de pesquisa, estado brasileiro, região do país e os principais autores e a quantidade de livros publicados referente ao tema nos CIPA's já realizados.

\section{Resultados}

A publicação de artigos sediados no Portal CAPES abordando narrativas formativas teve seu início no ano de 1994, e entre o período de 1994 a 2008 observa-se relativamente constante a quantidade de artigos publicados e revisados por pares, o que pode caracterizar o denominado período de eclosão na utilização desse método em pesquisas acadêmicas.

De acordo com dados coletados no Portal de Periódicos CAPES a partir do ano de 2009 percebe-se um aumento significativo no número de artigos, porém até o ano de 2015 ocorrem oscilações quanto à quantidade de publicações, o que indica ser o chamado período de fundação.

Já no ano de 2016 há um aumento expressivo de artigos publicados, que apresenta uma constância e provavelmente revela o período de desenvolvimento das narrativas formativas, conforme ilustra o Gráfico 1: 


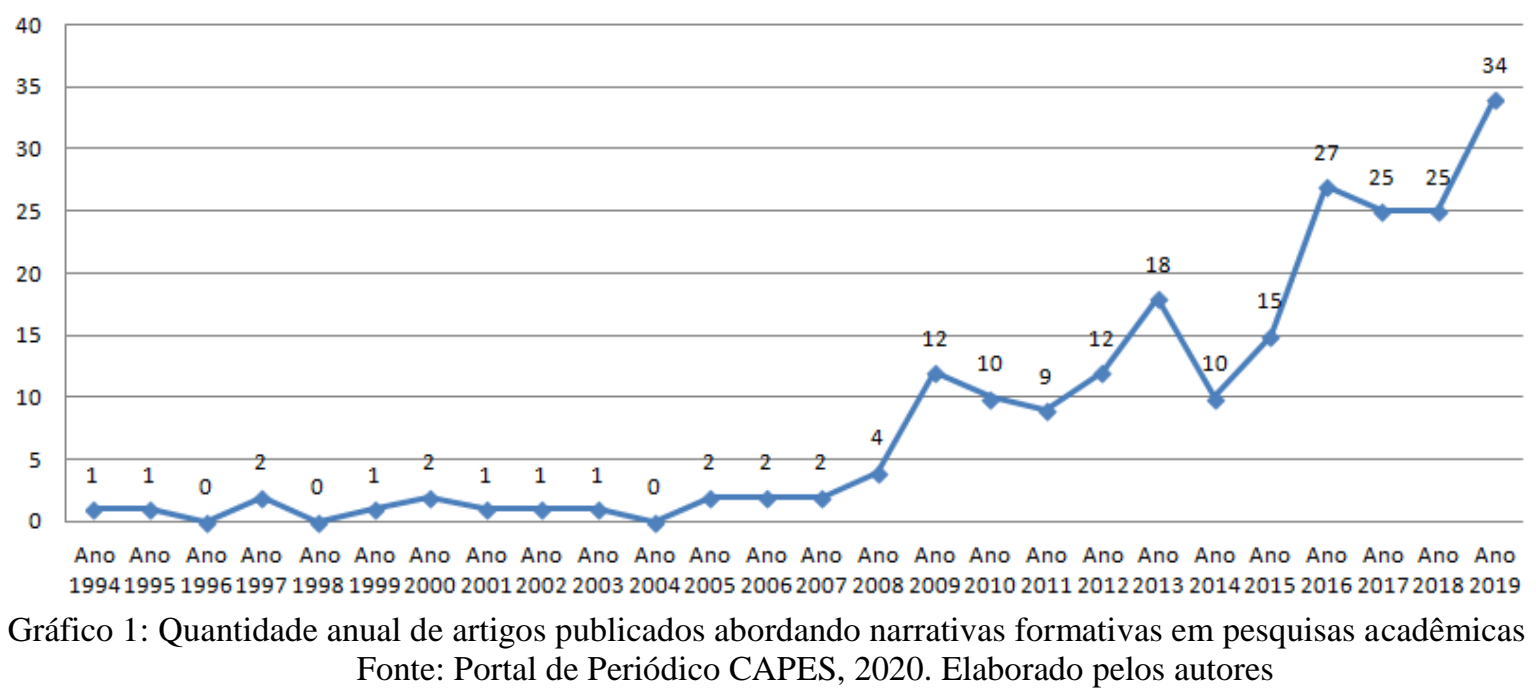

Quando se estabelece o contexto brasileiro como perspectiva de análise, o período de eclosão das narrativas formativas pode ser evidenciado com a constituição do CIPA no ano de 2004, assim, a partir do ano de 2005 percebe-se o aparecimento de publicações com estudos que aplicam as narrativas formativas como recurso de pesquisa. Até o ano de 2007 observa-se que o número de publicações que utiliza este método em pesquisas acadêmicas é pequeno. Após a criação da Associação Brasileira de Pesquisa (Auto) Biográfica BIOgraph, no ano de 2008, nota-se que no ano seguinte, 2009, há um aumento significativo no número de artigos sediados no Portal CAPES abordando a temática narrativas formativas.

No intervalo temporal entre os anos de 2009 a 2015 ocorrem oscilações quanto à quantidade de publicações de artigos, o que aparenta ser o chamado período de fundação da utilização desse método de pesquisa na comunidade científica brasileira. É também nesse mesmo período que duas coleções de livros sobre narrativas e pesquisa (auto) biográfica são lançadas tanto no Brasil, como na França e Argentina.

A partir do ano de 2016, há um aumento expressivo de artigos publicados, que fazem uso das narrativas formativas em estudos científicos, e esse número permanece em ascensão até atualmente, o que provavelmente revela o período de desenvolvimento das narrativas formativas no Brasil, conforme ilustra o Gráfico 2: 


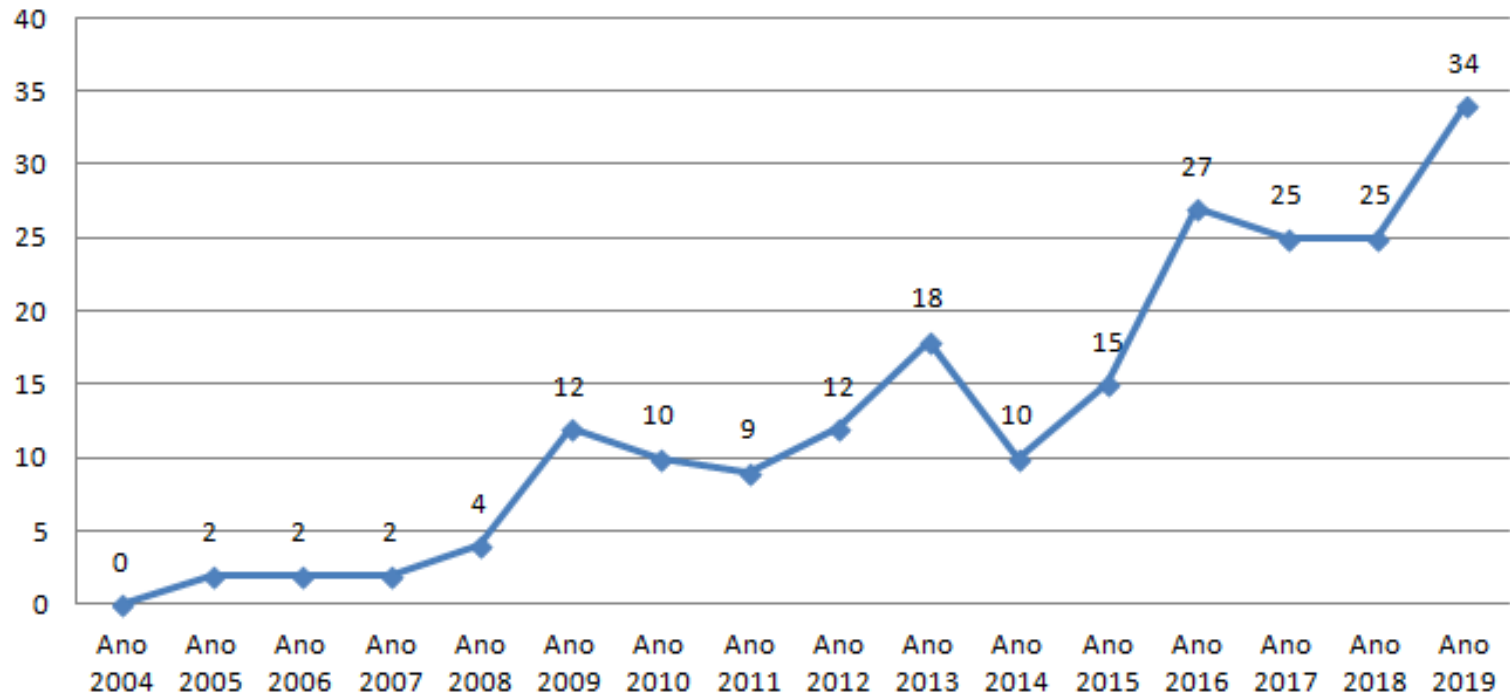

Gráfico 2: Recorte temporal da quantidade anual de artigos publicados abordando narrativas formativas em pesquisas acadêmicas após criação do CIPA

Fonte: Portal de Periódico CAPES, 2020. Elaborado pelos autores

Observa-se que a cada edição do CIPA, de periodicidade bienal, há a participação crescente do número de instituições de ensino superior nesse evento, o que pode indicar a atuação efetiva da Associação Brasileira de Pesquisa (Auto) Biográfica Biograph em promover e coordenar estudos e pesquisas, eventos e ensino no campo da pesquisa (auto) biográfica, memória, histórias de vida, narrativas formativas e práticas de formação na comunidade científica brasileira, como demonstra o Gráfico 3:

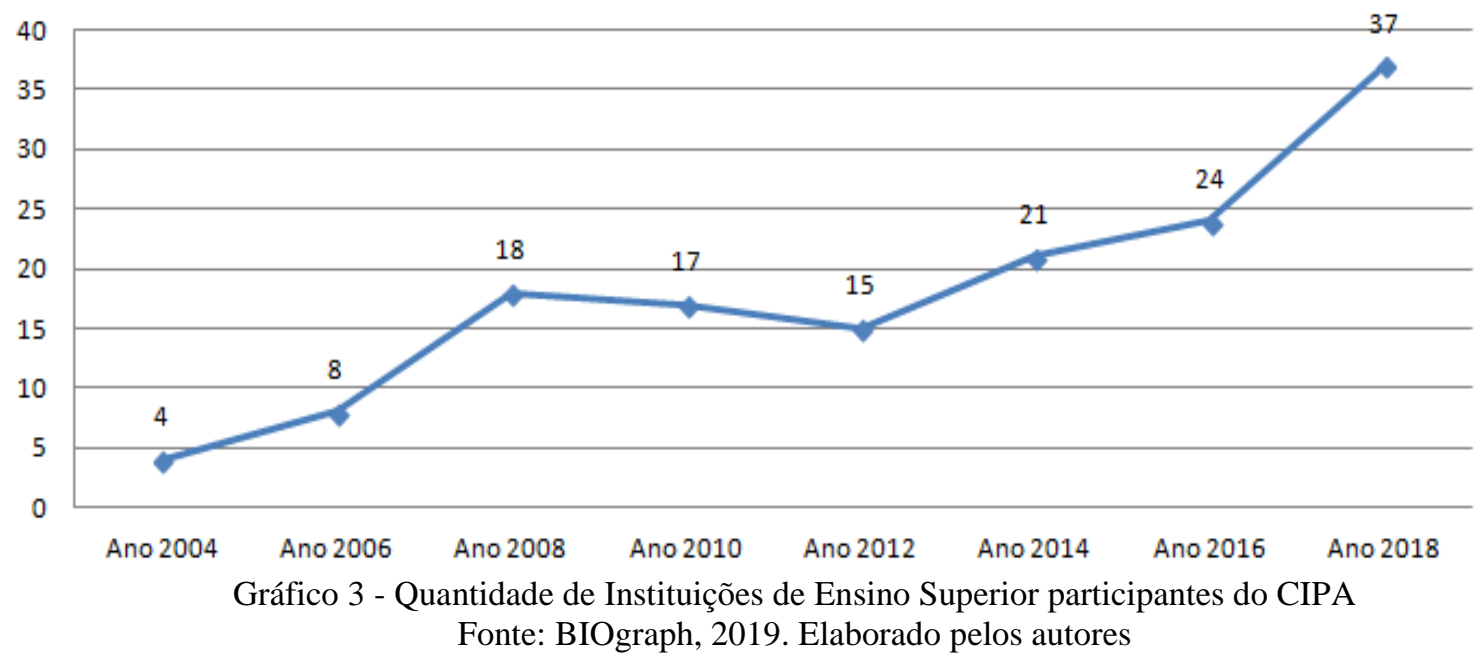

Verifica-se que a área do conhecimento que apresenta maior quantidade de artigos é a Educação com 51,15\%, seguida de Ciências Sociais com 15,7\%, Comunicação com 13,4\%, 
Saúde com 6,5\%, Psicologia com 3,2\%, Tecnologia com 2,3\%, Antropologia com 1,4\%, Administração, Artes, Artes Cênicas e Sustentabilidade com aproximadamente $1 \%$ e Astronomia, Ciências Econômicas, Filosofia, Linguística e Literatura com apenas 0,5\%, conforme demonstra o Gráfico 4:

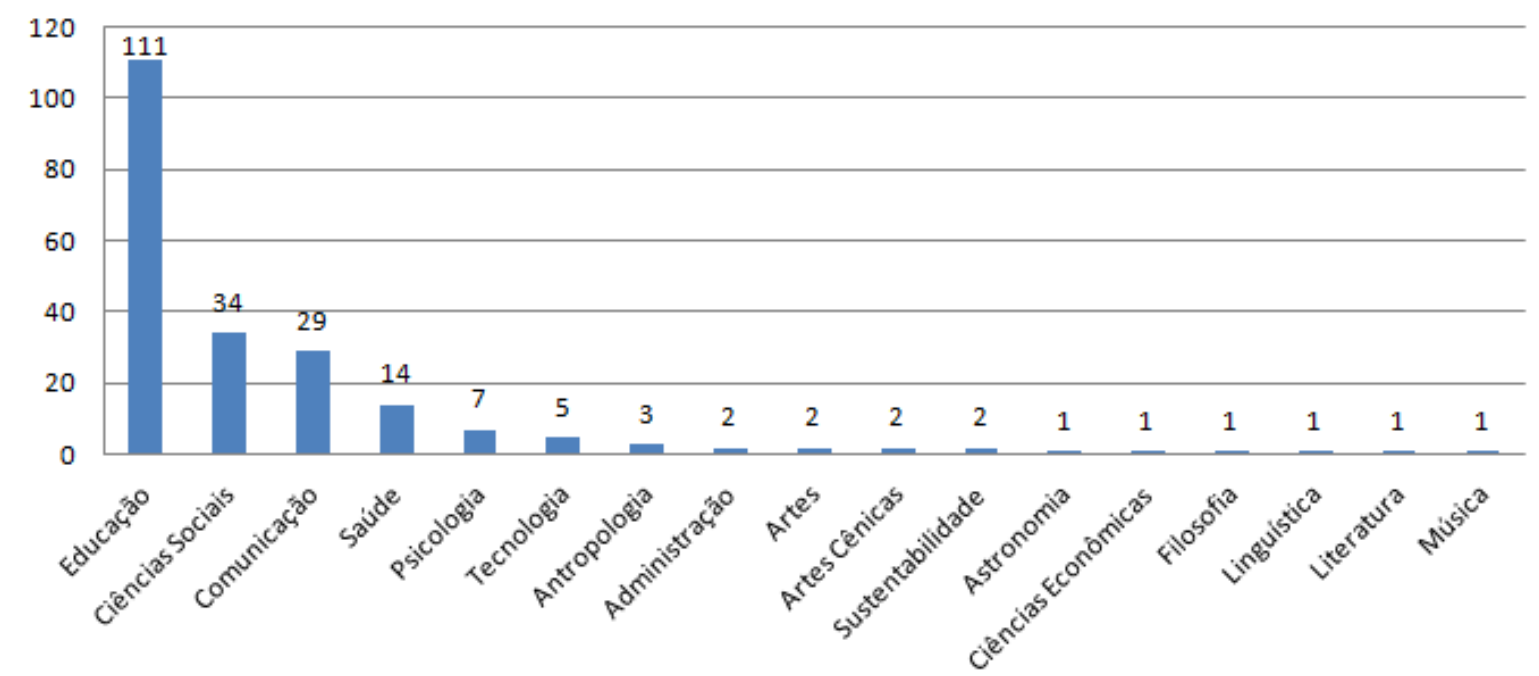

Gráfico 4 - Frequência dos artigos abordando narrativas formativas por área do conhecimento Fonte: Portal de Periódico CAPES, 2020. Elaborado pelos autores

No Brasil há um total de 27 grupos de pesquisas referente à pesquisa (auto) biográfica, memória, histórias de vidas, narrativas formativas e práticas de formação, distribuídos nas cinco regiões do território nacional, o que impulsiona a divulgação e fluxo de informações entre estes grupos de pesquisa, além de permitir o desenvolvimento e crescimento desse método e fenômeno de pesquisa na diversidade dos contextos educacionais, sociopolíticos e econômico-culturais em todo país.

Conforme ilustra o Gráfico 5, as regiões sudeste, sul e nordeste apresentam a maior representatividade dos grupos de pesquisa de pesquisa (auto) biográfica, memória, histórias de vidas, narrativas formativas e práticas de formação no Brasil, o que pode ser justificado devido ao fato da primeira edição do Congresso Internacional sobre Pesquisa (auto) biográfica ter ocorrido na cidade de Porto Alegre, no Rio Grande do Sul, e com a participação somente de instituições de ensino superior da região sul do país. Além disso, vale destacar que a Associação Brasileira de Pesquisa (Auto) Biográfica BIOgraph foi fundada no terceiro CIPA ocorrido na cidade de Natal, no Rio Grande do Norte e tem sua sede na cidade de Salvador, Bahia. 


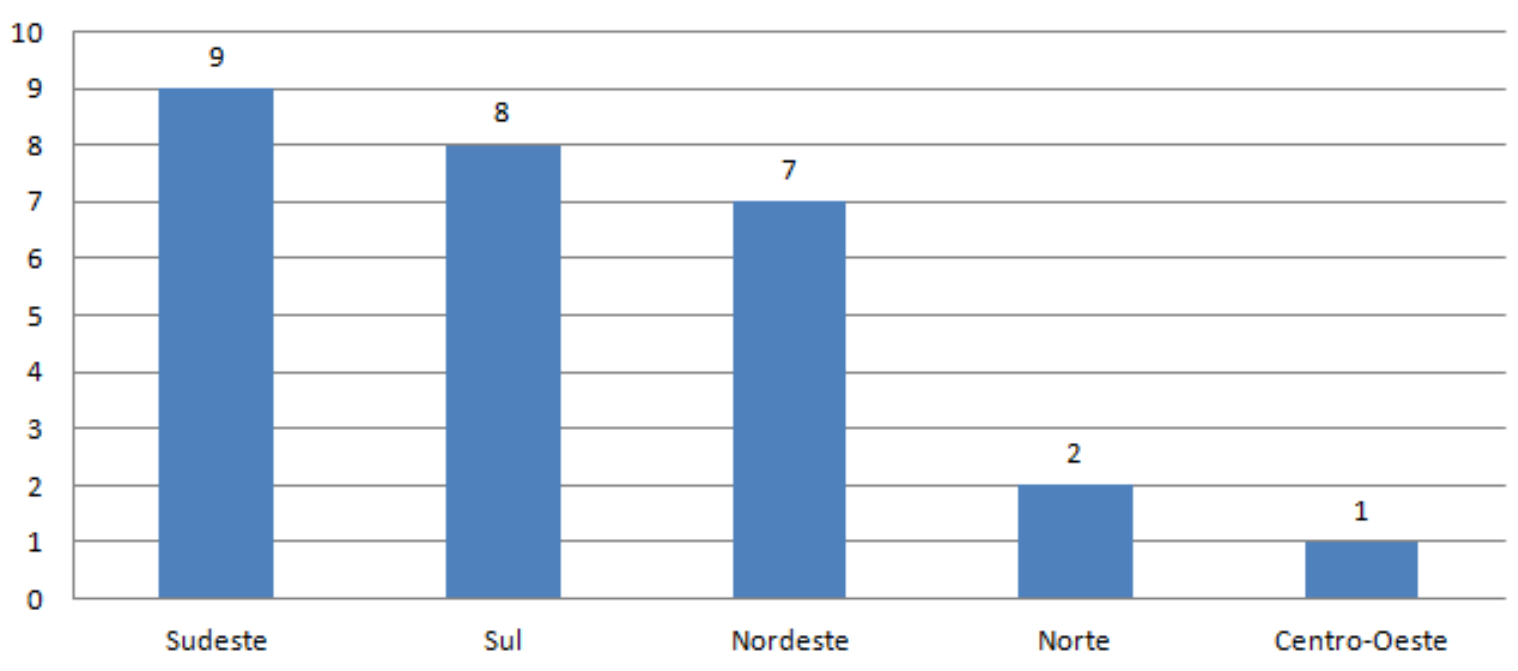

Gráfico 5 - Grupos de Pesquisa de Pesquisa (Auto) biográfica no Brasil Fonte: BIOgraph, 2019. Elaborado pelos autores

Ao realizar um recorte na área de educação, nota-se que a educação superior com $67,6 \%$, apresenta-se o setor com mais artigos publicados que abordam as narrativas formativas em suas pesquisas. A educação básica é representada com $23,4 \%$, a educação infantil com $5,4 \%$ e por fim, a educação profissional com apenas 3,6\%, de acordo com Gráfico 6:

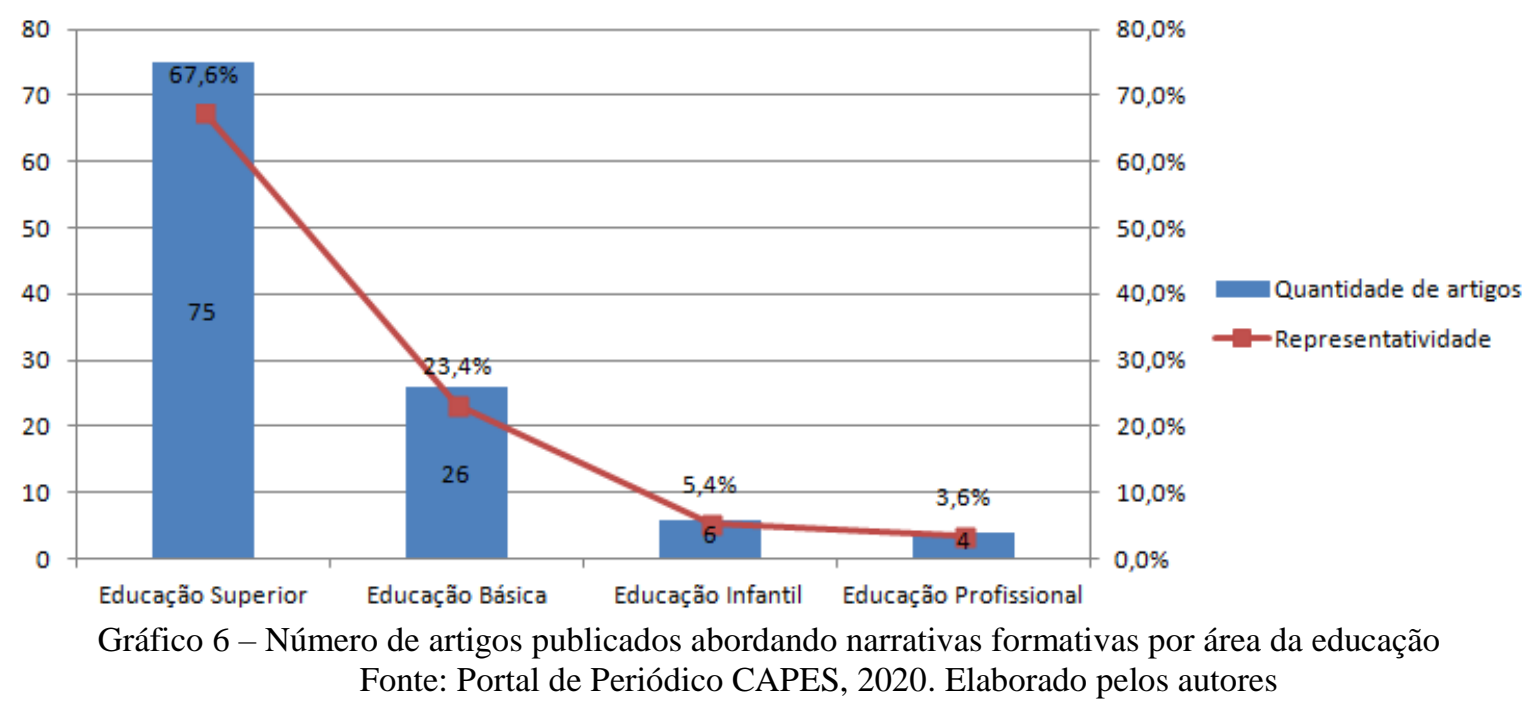

Apesar das narrativas formativas serem abordagens predominantes na área de educação $(51,15 \%)$, em contra partida são menos e até pouco utilizadas em outras áreas do conhecimento. Porém, nota-se que existem poucos estudos com a abordagem de narrativas formativas na educação profissional $(3,6 \%)$ o que possivelmente pode indicar a necessidade de explorar mais essa temática nesse contexto.

Revista Devir Educação, Lavras, vol.4, n.2, p.14-33 jul./dez., 2020. 


\section{Considerações finais}

Observa-se um recente crescimento (85\%) na utilização das narrativas formativas como recurso de coleta de dados nas pesquisas acadêmicas nos últimos quatros anos, o que aponta um possível desenvolvimento e reconhecimento desse método na comunidade científica.

Com as edições já realizadas do CIPA foram publicados um número significativo de livros e artigos em periódicos brasileiros e internacionais que constituem obras de referência na área.

De 2004 até o momento, observa-se, cada vez mais visíveis, os resultados do CIPA e da Associação Brasileira de Pesquisa (Auto) Biográfica BIOgraph, que contribuem para a divulgação e produção científica na área por meio da publicação de livros e artigos, além da criação de coleções referentes ao tema publicadas na França, na Argentina e no Brasil.

Também como desdobramentos, de acordo com os dados fornecidos pela BIOgraph, tem-se a consolidação de intercâmbios entre grupos de pesquisa em âmbito nacional e internacional para a realização e êxito das pesquisas (auto) biográficas, memórias, histórias de vidas, narrativas formativas e práticas de formação que se apresentam em plena expansão.

A pesquisa demonstrou que as narrativas formativas são abordagens predominantes na área de educação $(51,15 \%)$, em contra partida, pouco aplicadas em outras áreas do conhecimento.

Nota-se que existem poucos artigos que abordam as narrativas formativas em estudos e pesquisas na educação profissional (3,6\%), enquanto na educação superior $(67,6 \%)$ são mais expressivas sua utilização.

As narrativas formativas estão em expansão na comunidade científica, como também no contexto brasileiro, podem ser abordadas em diversas áreas do conhecimento, sendo mais concentradas na área da educação. Porém, as narrativas formativas podem contribuir e serem mais exploradas em estudos e pesquisas como instrumento de coleta de dados para a formação de docentes na educação profissional, já que a formação destes profissionais se dá de forma especial e emergencial.

No contexto de educação profissional, observa-se a importância do desenvolvimento da formação para a profissionalização na docência, considerando que os docentes são construtores de seu saber e de sua identidade profissional. Este processo é dinâmico e 


\section{OD DEVIR EDUCAÇÃO \\ ISSN: 2526-849X}

constante, em que os professores adéquam suas formações às exigências de sua atividade profissional, bem como do meio social que estão inseridas.

As narrativas formativas voltam-se tanto para o mundo do trabalho como para o acadêmico, essas podem sim contribuir e serem mais exploradas em estudos na área de educação. Particularmente na educação profissional, podem estar presentes tanto como instrumento de coleta de dados quanto para a formação de docentes do ensino técnico e tecnológico.

Portanto, compreender de modo narrativo as práticas e a vida de cada professor implica narrar os processos de constituição e desenvolvimento profissional no exercício da docência, destacando as singularidades, tensões e circunstâncias ao longo de sua trajetória de vida e prática pessoal e profissional. Nesse sentindo, é necessário dar-lhes voz e vez na investigação dos processos de formação dos professores. Uma possibilidade para isso tem sido a análise das narrativas formativas em que o desenvolvimento profissional e sua aprendizagem docente tornam-se eixos analíticos.

\section{Referências}

ANTUNES, Maria Pinto. Histórias de vida ou método (auto) biográfico: uma experiência na formação de educadores de adultos. Revista Roteiro, Joaçaba, v.36, n.1, p. 33-54, jan./jun. 2011. Disponível em: https://portalperiodicos.unoesc.edu.br/roteiro/article/view/787/pdf_116 Acesso em: 26 out. 2019.

ARAÚJO, Carlos Alberto. Bibliometria: evolução histórica e questões atuais. Revista Em Questão. Porto Alegre, v. 12, n. 1, p. 11-32, 2006. Disponível em: <https://dialnet.unirioja.es/servlet/articulo?codigo=6134719> Acesso em: 13 jul. 2019.

BARBISAN, Carla; MEIGID Maria Auxiliadora Bueno Andrade. Categorias de narrativas: principais usos em pesquisa e formação de pedagogas. Educação Temática Digital, Campinas, v.20, n.4, p979-996, out./dez. 2018.

BIOGRAPH. Associação Brasileira de Pesquisa (Auto) Biográfica. 2019. Disponível em: <https://www.biograph.org.br> Acesso em: 15 nov. 2019.

CAPES. Portal de Periódicos da Capes. 2020. Disponível em: <http://www.periodicos.capes.gov.br/> Acesso em: 16 jun. 2020.

Clandinin, D. Jean; CONNElly, F. Michael. Pesquisa Narrativa: Experiências e história na pesquisa qualitativa. $2^{\text {a }}$ ed., edUFU. Uberlândia, 2015. 
DEWEY, John. Democracia e Educação. Experiência e Pensamento. Capítulo 11. Disponível em: http://www.educ.fc.ul.pt/docentes/opombo/hfe/dewey/cap11.htm Acesso em: 04 de abril de 2020.

FERNANDES, Natal Lánia Roque; LOPES, Maria Amélia. As narrativas de formação nos processos formativos de professores como dispositivo para a reflexão sobre a aprendizagem da docência na educação de jovens e adultos. Salvador: UFBA, 2011. (R. FACED, n.20, p. 35-49, jul./dez. 2011).

FIORENTINI, Dário; CRECCI, Vanessa. Desenvolvimento Profissional docente: um termo guarda-chuva ou um novo sentido à formação?.Revista Brasileira de Pesquisa sobre formação docente. Belo Horizonte, v.5, n.8, p. 11-23, jan/jun 2013. Disponível em: http://formacaodocente.autenticaeditora.com.br Acesso em: 04 de abril de 2020.

GATTI, Bernadete Angelina; BARRETTO, Elba Siqueira de Sá. Professores do Brasil: Novos cenários de Formação. Brasília: UNESCO, 2019. Disponível em: http://www.unesco.org/new/pt/brasilia/about-this-office/single-

view/news/professores_do_brasil_novos_cenarios_de_formacao/. Acesso em 24 nov.2019

JOSSO, Marie-Christine. Experiências de Vida e Formação. São Paulo: Cortez, 2004.

JOSSO, Marie-Christine. A transformação de si a partir da narração de histórias de vida. Educação, Porto Alegre, ano XXX, n.3 (63), p. 413-438, set./dez. 2007. Disponível em: https://wp.ufpel.edu.br/gepiem/files/2008/09/a_tranfor2.pdf Acesso em: 02 nov. 2019.

LANGHI, Celi; MACEDO, Elaine de Fátima Soares. Aprendizagem Ativa na educação profissional: um estudo bibliométrico dos artigos sediados pelo Portal de Periódicos Capes. São Paulo, outubro de 2018. In: Anais do XIII Workshop de Pós-Graduação e Pesquisa: Práticas de Educação Profissional e Tecnológica e Educação Corporativa. Disponível em: http://www.portal.cps.sp.gov.br/pos-graduacao/workshop-de-pos-graduacao-e-pesquisa/013workshop-

2018/artigos/Educacao/Praticas_Educacao/Aprendizagem_Ativa_na_educacao_profissional.p df Acesso em: 10 jul. 2019.

LARROSA, Jorge Bondia. Notas sobre a experiência e o saber de experiência. Revista Brasileira de Educação, n.19 jan-abr, 2002. Disponível em: http://www.scielo.br/pdf/rbedu/n19/n19a02.pdf Acesso em: 04 de abril de 2020.

LIMA, Maria Emília Caixeta de Castro; GERALDI, Corinta Maria Grisolia; GERALDI, João Wanderley. O trabalho com narrativas na investigação em educação. Educação em Revista, Belo Horizonte, v.31, n.01, p.17-44, janeiro-março 2015.

MIZUKAMI, Maria da graça Nicoletti. Aprendizagem da docência: professores formadores. Revista E-curriculum, São Paulo, v.1, n. 1, dez-jul. 2005-2006. Disponível em: http://www.pucsp.br/ecurriculum Acesso em: 15 mai. 2019. 
MIZUKAMI, Maria da Graça Nicoletti. Escola e desenvolvimento profissional da docência. In: GATTI, B. et al.(Org) Por uma política nacional de formação de professores. São Paulo: editora UNESP, 2011. Cap. 1, p.23-54.

NÓVOA, Antonio. Formação de professores e profissão docente. In: NÓVOA, Antonio (Org). Os professores e a sua formação. Lisboa. Dom Quixote, 1992, Cap.1, p. 15-33.

PAIVA, Cantaluce Mércia Ferreira. A identidade docente na educação profissional: como se forma o professor. XVI ENDIPE - Encontro Nacional de Didática e Práticas de Ensino UNICAMP, 2012.

PETEROSSI, Helena Gemignani; MENINO, Sergio Eugenio. A formação do formador. São Paulo, SP: Centro Paula Souza, 2017.

RAMIREZ, Rodrigo Avella. Histórias de Vida na formação do professor. São Paulo: CEETEPS, 2014.

RAMIREZ, Rodrigo Avella. Aprendizagem da docência: a língua inglesa no ensino superior tecnológico: experiências, práticas e desafios. 2017. 215 f. Tese (Doutorado em Educação, Arte e História da Cultura) - Universidade Presbiteriana Mackenzie, São Paulo, 2017.

SHULMAN, Lee. Conhecimento e ensino: fundamentos para a nova reforma. Cadernos Cenpec. São Paulo, v.4, n.2, p. 196-229, dez. 2014.

TARDIF, Maurice. Saberes docentes e formação profissional. 17. ed. Petrópolis, RJ: Vozes, 2014.

Recebido em: 02/10/2020

Aprovado em 15/11/2020 